DOI: $10.21625 /$ resourceedings.v1i1.178

\title{
LAND SUITABILITY ANALYSIS AS MULTI-CRITERIA DECISION MAKING TO SUPPORT THE EGYPTIAN URBAN DEVELOPMENT
}

\author{
Marwa Adel El Sayed ${ }^{1}$ \\ ${ }^{1}$ The British University in Egypt, Cairo, Egypt
}

\section{Keywords}

Multi-Criteria Decision Making, Geographic Information System, Land Suitability Analysis, City Location;

\begin{abstract}
Sustainability in urban development is considered as the main concrete stone that directly affects the quality of life for its users. Land Suitability Analysis (LSA) using GIS as a multi-criteria support tool reveals the best alternatives for the suitability of sustainable land development. Urban planners working under the umbrella of sustainability using recent technology should contribute their work directly to LSA. This paper aims to develop a new technique to be used by planners to reach the best alternative for five main urban sectors (agriculture, industry, trade, tourism, \& residential) using GIS as a multi-criteria decision support tool (MCDS). This will, accordingly, help in choosing the best city location that will be accurately analyzed upon LSA studies. LSA and MCDS are going to be applied to one survey unit map called Monof along Cairo - Alexandria Road. Results showed that different alternatives could be applied on the area of interest and all of them are sustainable, but choosing the best deepened on the priority of querying the development sector. The paper suggests a pilot method for land development planning and choosing the best city location that would be a guide for the governmental planning organizations to support in taking correctly analyzed planning decisions.
\end{abstract}

\section{Introduction}

The demand for constructing new cities is determined primarily by population growth, geographic distribution, land potential availability, and current and proposed infrastructure (Martos et al. 2016). While the number of residents living at an acceptable quality of life in new cities relies mainly on the type of services that the city can offer to them, these services, to be at an adequate level, should be based on concrete economic bases which are directly related to the city location potential and constraints (Mrkajić \& Anguelovski, 2016). For planners to be properly responsive to these potentials and constraints, LSA should be done first based on new planning methods and techniques. One of these techniques that will be discussed in the paper is the power of using GIS in LSA with the help of Multi-Criteria Decision Making (MCDM) to reach optimum land distribution for the main urban development sectors (agriculture, industry, trade, tourism and residential). These sectors will be the economic nucleus for building new cities which, in turn, will directly affect the type of services that the city will offer to its residents. In Egypt, extensive overbuilding of new cities without concrete studies for LSA based on both GIS and MCDM has been argued to be one of the reasons that are responsible for the failure of most of these cities to reach their target population (Khalifa 2011). This vision drives much active research in the LSA field.

During the last three decades, the Egyptian government has established 24 new cities that have already been constructed and seven other cities are under construction now. According to (NUCA, 2016), almost none of these cities have reached their target population number in spite of the great efforts from the government to attract as many residents as possible to avoid overcrowding in their original cities. Recent research has shown that Egyptians are losing their life quality in the new cities as these cities do not fulfill their needs (Mahmoud \& El-Sayed 2011). 
LSA depends mainly on GIS with the help of MCDM as a tool to determine the land suitability for urban development of a certain area. It shows the suitability of an area regarding its potentials and constraints (Liu et al. 2014). LSA is also related to a lot of fields including economics, environmental fields, and social factors (Romano et al. 2015). This research investigates a method for reaching the optimum urban development usage to maintain new cities upon LSA studies that are considered as the nucleus that will offer the best services for its residents.

\section{Research Problem:}

New cities in Egypt mainly suffer from the misdistribution of activity development sectors that, in return, affects the number of citizens living in it. Accordingly, the research tries to offer a new method for the planners to help them hand an appropriate planning decision for land distribution to finally reach the most suitable location for new cities. This method is based on GIS as a tool to reach the best urban development distribution as the research's main objective relies on reaching the LSA for the area of interest not only through the planner's view but also by collaborations between planner sand activities professionals' different point of views to finally reach the best city location.

\section{History of Emerging GIS in the Planning Field:}

There are three periods in the modern era that were divided emerging the GIS technology in the planning field, the first one is called "the GIS research frontier period" that referred to the innovative stage in $1950-1970$ s. The second period is called "the development of general- purpose GIS systems" that referred to the integration stage in the 1980s, and the last period is called "the proliferation stage" which was mainly focused on the development of the users to deal with GIS technology (Malczewski 2004).

The role of GIS in planning has been emerged through changing the planning view from being a scientific approach to multi-criteria collective data approach (RK Brail 2001). Changing the planning view requires a real computer technique to be applied as a response to multi-criteria collective data. The development of mapping computer technique started in the Harvard Laboratory especially to develop the LSA (Malczewski,2006). Murray et al., 1971 have stated that the Harvard Laboratory proposed their early application on suitability analysis for recreation and different land uses based on the flood-control studies and parkways (Cristea \& Jocea 2016), while in 1972 Niemann proposed a first overlay analysis in the planning field. Afterwards, in 1980, Massam suggested the overlay technique in the location analysis then in 1983 Lyle and Stuz developed an application for LSA in the field of planning (Zabihi et al. 2015). In 1990 Tomlin functioned the overlay approach using the mapping technique to produce the LSA maps applied with a weighted linear combination which simplifies the complexity land use planning problems (Malczewski 2004).

Nowadays, the planning field is associated with the participation of different parties from different fields, which may be relatively unrelated to planning (stakeholders, interest groups, governmental organization, nongovernmental organization, public, citizens, and different development sectors experts), but their role is very important in helping the planner to take the right decision. This new planning vision evolved in parallel to the evolution of GIS technology, which gives the planner the opportunity to collect all the planning parties' visions and overlay them to finally reach the optimum right decision (Xu \& Li 2014). In the recent era of using GIS in the planning field, it was just a routine digital task of mapping and querying but nowadays GIS offered a modeling database using MCDM to increase GIS capabilities in simulation, analysis, statistics, and optimization concerning planning (Xu \& Li 2014).

From the LSA perspective, converting the real world into a vector and attribute data, this was the start point for the overlay technique that is considered afterward the concrete stone to apply an accurate land suitability analysis. Moreover, applying the raster data in LSA plays an important role in supporting the overlay technique as the raster data can be vectorized and vice versa (Jafari \& Zaredar 2010).

\section{GIS Trends and Challenges for Land Suitability Analysis:}

Land suitability for mapping and analysis is considered one of the most popular applications in GIS concerning urban planning and management (RK Brail 2001). Land suitability analysis using GIS has been applied in a wide variety of areas besides planning like land suitability for plant species, animals, agriculture field, geological studies, environmental impact assessment, and landscape planning and design (Malczewski, 2004).

In LSA, it is important to distinguish the difference between the site selection analysis and site search analysis because it is considered as the primary main step in choosing the best new city location (El Baroudy 2016). The main aim of site selection analysis is to be able to identify the best urban development sector that suites the area of interest potentials and constraints. The main issue that may face the planner is having more than one alternative for 
the same area of interest, so it comes now to how he can rank these alternatives to reach the best that could offer the highest economic base for the new city location. Concerning the site search analysis aim, it is related to the best site location boundaries and its characteristics (Javadian et al. 2011). Both site selection and search analysis deal with a given study area that is divided into a set of units such as polygons or rasters and the research will deal with 'Monof' area as one survey unit.

Over the last fifty years, GIS land suitability analysis has become a main tool for the planners to integrate the components of environmental, regional, and urban planning development sectors, (RK Brail 2001). GIS overlay techniques were first used in the late nineteenth by the American planners as the main root to LSA approach (Xu \& Li 2014). Woodfin 1993 used the GIS overlay technique in an advanced way by presenting maps that include both human-made and natural data and attributes using dark and light shading showing the suitability analysis to the area of interest. This method has been known as a classical overlay method in GIS. Tomlinson (1999) implies that his company Spartan Air Services of Ottawa was the first to propose the overlay method (Effat 2014)(Waters2002). The overlay tool plays an important role in a lot of GIS applications that are related to LSA such as multicriteria decision analysis (MCDA), visualization methods, artificial intelligence (AI) geo-computation methods, and WebGIS, (Xiao et al. 2002).

LSA is not only the planners' point of view, but it is considered as a collective opinion for different parties such as citizens, professional interest groups, developers, policymakers, and others. It cannot be summarized that LSA depends only on GIS procedure, but also it includes other professionals', and users' approaches (Jafari \& Zaredar 2010), and this will appear clearly later in the methodology section. GIS is considered as a software that improves the community public participation generally in planning and especially in LSA, and this participation is considered a political issue rather than a technological one (Montgomery et al. 2016). There is also a growing interest of GIS implications in LSA field that brought both the developers and practitioners to make a logical examination for the available data to reach right supportive planning decisions (Zabihi et al. 2015).

Finally, it can be summarized that GIS-based land-use suitability analysis is considered as a process of converting data into useful information that gives the decision maker great support to take the right planning decision. GIS overlay technique is also considered one of the useful tools that support MCDM in LSA and has the capabilities of combining the data into map-based GIS operations to be helpful in answering questions related to the land-use suitability analysis. This concluded statement reinforces (Broesamle et al. 2001) as they mainly reviewed three main branches which are two GIS overlay analyses, multi-criteria evaluation, and GIS LSA.

\section{Multi-Criteria Decision Making Techniques Integrated with GIS in LSA Field:}

MCDM has been integrated with GIS to produce an overlay map approach and querying the database of this overlay map by combining different views for all the development sectors expertise's (Xu \& Yang 2001). The marriage that combined both MCDM and GIS technique has the ability to transform both spatial and non-spatial data into a fully supported decision that can be a great tool for the planners to work with (Temiz \& Tecim, 2009). This is given that the MCDM technique can support the GIS capabilities for data analysis, recapture, repository, manipulation, and acquisition, and GIS can successfully deal with combining different views for planner participants and reach the best decision from this combination. LSA is considered one of the important issues that both MCDM and GIS can deal with successfully. MCDM is not only integrated with overlay vector application of GIS, but it is also integrated with Raster analysis application for evaluating the LSA resulted in features using weighted sum technique to be able to assign successful weights to the different planning dimensions (Xu \& Yang 2001). Lately, multi-attribute evaluation methods have been successfully implemented in the planning field using GIS as a successful tool to apply that kind of analytic hierarchy analysis to finally reach the optimum planning decisions (RK Brail 2001). Analytic hierarchy analysis has a closed relationship to LSA as it can be implemented to assign the weights of suitability for map attribute that can be presented by means of raster data to be ready for the weighted sum technique. It can also help in determining the priority level of the planning points included in LSA (Chaudhary et al. 2016). Planners have pointed out some problems that are associated with implementing GIS with MCDM, these problems initially appear in the inaccuracy and ambiguity of importing multi-attribute data to the database (Wanderer \& Herle 2015). Secondly, it is related to the criteria standards that differ from one planner's approach to the other that finally lead to different land uses for the same area of interest (Temiz \& Tecim 2009). This research paper will address this point in the case study application using a co-relation matrix. The third and last problem is represented in the overlay techniques that used to apply MCDM practically in GIS as the same weights are assigned to all the map attributes (Temiz \& Tecim 2009). This research paper will also address this problem by applying the raster analysis using the weighted sum technique.

During the last decade, recent researchers have developed approaches that integrate the GIS with MCDM in the LSA field (Aydin et al. 2013). These approaches are the fuzzy logic techniques, neural networks techniques, Evolutionary algorithms, and Cellular automata. Regarding the fuzzy logic technique, one of the main criticisms 
that face integrating both GIS with MCDM in the LSA field is importing the accurate input data for the area of interest which is, of course, unrealistic. For example, natural boundaries between suitable and unsuitable areas are not found in reality as a cut- off as it is drawn in the database, however locating a suitable site from the main road $1 \mathrm{Km}$, may be in reality $0.98 \mathrm{Km}$ and maybe $1.02 \mathrm{Km}$. That is why the fuzzy logic technique in such cases is much more precise (Çekmiş 2016). The fuzzy technique is considered as the possibility of defining a range without clear boundaries, for example, assigning a value for the target area between 0 and 1 helps in treating the missing information with interpolation the ranges in-between (Ning et al. 2016). According to Nasibov, Diker, \& Nasibov, 2016 three approaches are introduced to assign the fuzzy technique in LSA field, these are an experimental analysis, the similarity relation model, and the semantic import model.

The second approach is the neural networks technique that is mimicked from the human brain simulation as the individual planning elements are joined by a different weight (Yeo \& Yee 2014). These techniques convert the reality into the database through three steps input, model, and output. Martos, Pacheco-Torres, Ordóñez, \& Jadraque-Gago, 2016 have found that the neural network technique is an effective tool to apply MCDM in the LSA field; their experiment shows that GIS's traditional ways could be replaced by the neural network as it proposes solutions to the complex LSA problems. The third approach is the evolutionary algorithms approach that is adapted from the biological natural evolution (Xiao et al. 2002). MCDM has been integrated with evolutionary algorithms as the resulted solutions only from evolutionary algorithms are poor, but by combining and mutating MCDM with this technique, good solutions for any planning problems are generated and developed upon scientific bases (Duan \& Huang 2014). This combination has gained popularity in the LSA field according to its capability in identifying a specific site for adaptable activities (Xiao et al. 2002). Later on, Nguyen et al. 2015 apply GIS as a tool to generate an evolutionary planning multi-criteria model better than using the conventional traditional planning ways, as GIS analyzed the LSA problems in both attribute and geographical spaces. The last approach is called cellular automata which consist of set cells in a one or multi-dimensional criteria, as these cells are considered spatial cells so they are involved in simulating urban development (Huang et al. 2014). Malczewski 2006 suggested integrating GIS as a powerful tool for applying cellular automata approach in LSA field. It is concluded that GIS has been evolved in LSA field recently through overlay modeling with the help of MCDM technique under the umbrella of any of the previously mentioned approaches.

The review of the literature reveals different methods have been applied in LSA field with the help of GIS and MCDA, accordingly the research attempts to present a new method to reach LSA fulfilling the potentials and constraints for the area of interest in Egypt. Therefore, this study aims to allocate new cities based on an analyzed concrete LSA to be able to decide the optimum economic bases for the city in Menof region as case application using GIS with the help of MCDM in the form of accumulative co-relation matrix between different development sectors and the area of interests' potentials and constraints.

\section{Methodology}

This research adopted a correlation multi-criteria professional mixed approaches using GIS and matrix as tools to reach the optimum LSA. The research accommodates different qualitative and quantitative set of data. Menof Region was chosen as a case study application. Accordingly, the case study has been through three applied phases as followed:

- Data collection phase: where a set of quantitative and qualitative data have been collected from different sources (maps, charts, statistics, reports,....etc).

- Data integration phase: where all the maps have been imported in the GIS in one database within its related feature dataset, then they are overlaid in one integrated feature class.

- Data query phase: In this phase, the MCDM is applied on the overlaid feature using the quires extracted from co-relation matrix.

\subsection{Case Study Background:}

The study area is Menof region in Egypt as shown in (figure 1). It lies in three Government (BEHARIA, EL MONOFIA, GIZA ) of about 975495.283465 acres. The study area includes Cairo Alexandria Road and surrounded area starting from Qubbet el Hasana protected area to El Sadat city. The area is chosen as it's one unit area which has its maps available without getting bounded to governmental or administrative borders. The area is taken as a pilot project that can be repeated on a national level. 


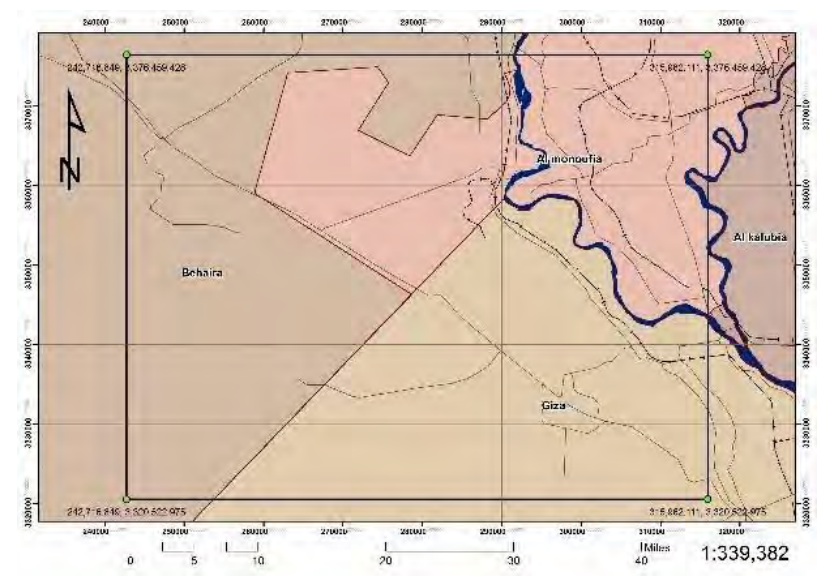

Fig. (1) Menof Region retrieved from arc map Source: researcher

The area of interest has been chosen for the many reasons:

- Unorganized urban development that appears within different activities (Agriculture - Industry - Trade Tourism - Residential) on both sides of Cairo Alexandria road without the existence of a planned strategy for this area that organizes this growth.

- The existence of large investment in the area that needs a kind of organization and planning to reach the optimum methodology to manage the area sources.

- Cairo Alexandria spine is considered the strongest among the other linear development spines coming out of Greater Cairo region.

- This spine passes through the highest density region and highest population and resources as well, and it is adjacent to west delta which is highly populated with people and labor which is highly populated with people and labor which can be used in the development process on the spine.

- Possibility of using this study as a part of the development suggested by Dr.Farouk ElBaz

\section{Correlation Multi-Criteria Professional Mixed Approaches Strategy:}

The researcher used ArcGIS 10.3 to build up LSA for Menof, the system is structured of many datasets, each contains GIS feature classes that are created or imported by Arc Catalogue, and then they organized systematically and logically into the datasets. With the help of the accumulative co-relation matrix, a relationship has been raised between both activities and constrain five development sectors (Agriculture, Industry, Trade, Tourism, and Residential). This matrix gives the researcher the opportunity to collect the different approaches for the professional's development sectors in one excel sheet to be easily applied on GIS. Applying such a methodology supports the decision-maker in finding the best suitability analysis for the area interest.

The coloration matrix uses binary code values defining the possibility of assigning a certain activity (agriculture, industry, tourism, residence) according to the environmental context and design specifications. Each column is populated by professionals in each sector. Binary codes consist of two numbers 1 or 0 .

\subsection{Data Collection Phase:}

This phase is considered the start phase in the practical part of the study, as the researcher started in the collection all the related maps, data, statistics concerning the area of interest, these data have been collected in different format ( raster, paper, Cad, Shapefiles, excel files, and word reports). All the previous mentioned data have been imported in GIS in one geodatabase and 11 feature dataset as shown in (fig 2), each map has been imported as a feature class in its related feature dataset and has been populated by its related attribute data. 


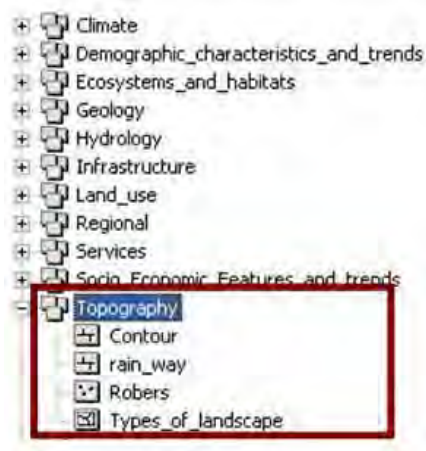

Fig (2) shows the proposed database

Source: Researcher

\subsection{Data}

This phase is considered the most important one, as it needs a high level of accuracy to prepare the overlay feature class. To get the overlay feature class for the area of interest as shown in (figure 3), it is required to have all the feature classes in polygon type. This means that all the point and line feature classes should be buffered with distances that are specified from professionals to define the extent of service or effect of these features such as rain ways, major Fault lines, metallic extraction points, building materials points, canals, touristic Points, airports, marines, rail-Ways, roads, electricity lines, roads, oil \& gas lines, and railways. Sliver gaps have resulted from the overlay lay operation, these gaps should be eliminated from the database to be ready for the query phase.

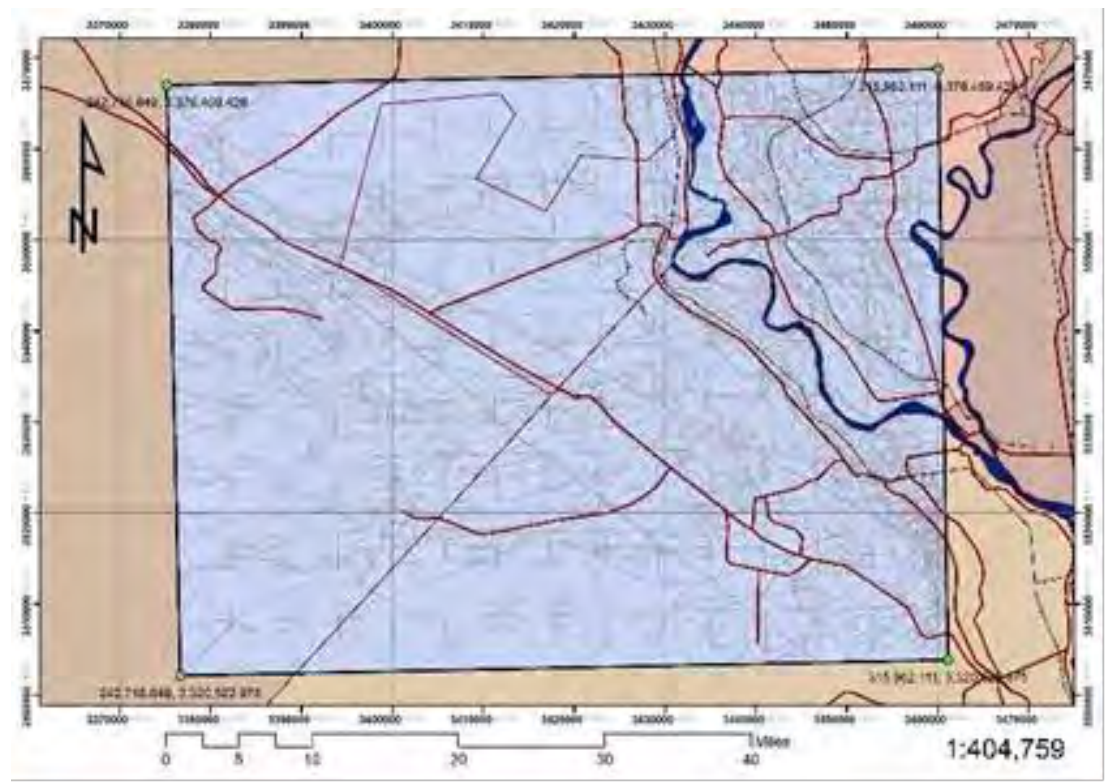

Fig (3) shows an overlay map of the area of interest

Source: researcher

\subsection{Data Query Phase:}

This is the last step in the practical part as now the database is ready for the query on the suitability of the land an example for the query is shown in (figure 4). As mentioned before the matrix has been populated by professionals in the different development sectors (Agriculture, Industry, Trade, Tourism, and residential). Now it comes to planner role to arrange his priorities and strategy to decide which development sector, he will query for first and which will come after. It is important to mention that changing the sector's priorities may give an infinite number of alternatives with right LSA, but the question here what is the best? And what are the factors that could the planer stands for to decide the best alternative? The answer depends mainly on the planner future strategy and his view towards the area of interest and the type of development that this area mainly needs. This phase gives a clear overview of the research main objective, which mainly depends on collaboration between the planner and activities' professional to take an optimum LSA decision with the help of GIS as a tool. The planner role is now specified in 
putting the strategy that will determine which activity sector will be queried first, and this will be discussed later in details in the next section.

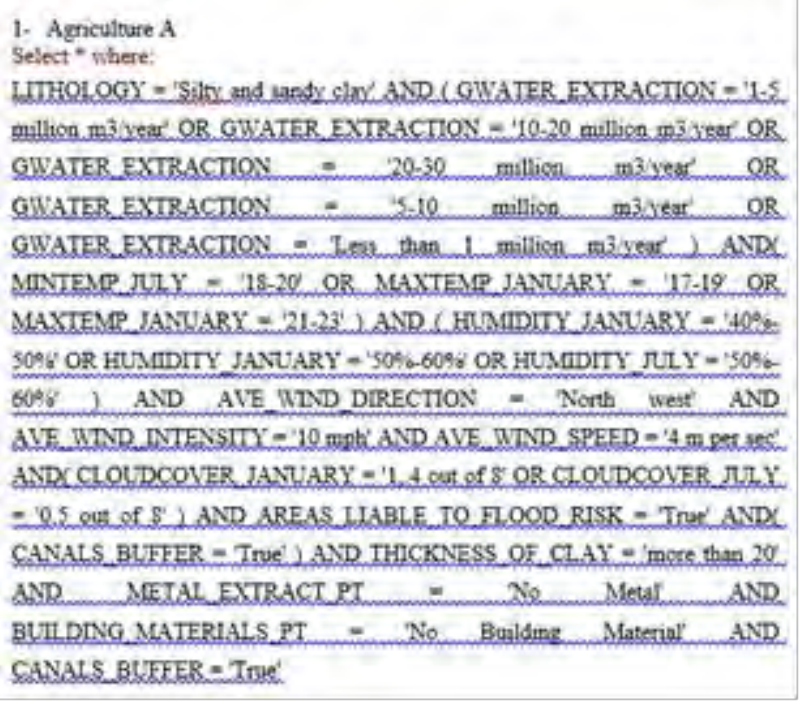

Fig (4) shows the query sematic

Source: researcher

\section{Results \& Discussion:}

After populating the matrix from professionals as mentioned before, the researcher has decided two different strategies the get two alternatives for the area of interest by changing the priorities of the development sectors according to each strategy. Each development sectors have been divided into three types as a start for applying this pilot methodology as shown in the following (table 1), but of course, it could be divided into more than three.

Table 1.shows the matrix development sectors description Source: Researcher

\begin{tabular}{|c|c|c|}
\hline \multirow[b]{4}{*}{ Agriculture } & Development Sector & Description \\
\hline & Agr A & Agriculture that depends on irrigation from river Nile \\
\hline & Agr B & $\begin{array}{l}\text { Agriculture that depends on irrigation from wells and } \\
\text { second type for }\end{array}$ \\
\hline & Agr C & $\begin{array}{l}\text { Agriculture that depends on irrigation from rain and third } \\
\text { type of soil }\end{array}$ \\
\hline \multirow[b]{3}{*}{ Industry } & Ind $\mathrm{A}$ & Extractive industry based on the natural materials. \\
\hline & Ind $\mathrm{B}$ & Transformative industry based on material extracted \\
\hline & Ind $\mathrm{C}$ & Agriculture industry based on crops that are cultivated \\
\hline \multirow[b]{3}{*}{ Tourism } & Tour A & Culture \\
\hline & Tour B & Health \\
\hline & Tour C & Recreation \\
\hline \multirow{5}{*}{ Trade } & Trade A & Export, depend mainly on transportation type A \\
\hline & Trade B & Local, depend mainly on transportation type B \\
\hline & Trade $\mathrm{C}$ & Wholesale, depend mainly on transportation type $\mathrm{B}$ or $\mathrm{C}$ \\
\hline & Res A & Luxurious \\
\hline & Res B & Average \\
\hline
\end{tabular}




\section{Res C}

Low

The first LSA planning strategy that was put by the researcher was firstly based on querying the agriculture with all its type as a first priority then asking for the three types of above-mentioned industries, afterwards searching for the potentials that will support trade with its three categories, followed by looking for touristic acids to support querying the three types of tourism, and finally exploring the best places that suites the residential development sector. Several results have been concluded from this trial, starting by the LSA suitable for each development sector and this is shown in the following (fig 5) and the area suitable for each sector which is shown in the following (table 2) and (Fig 6). Based on this type of analysis three main locations have been proposed for developing new cities with total area 19 KM2. Concerning the economic base for the proposed locations of the new cities, it will be related directly to the proposed LSA of its surrounding area.

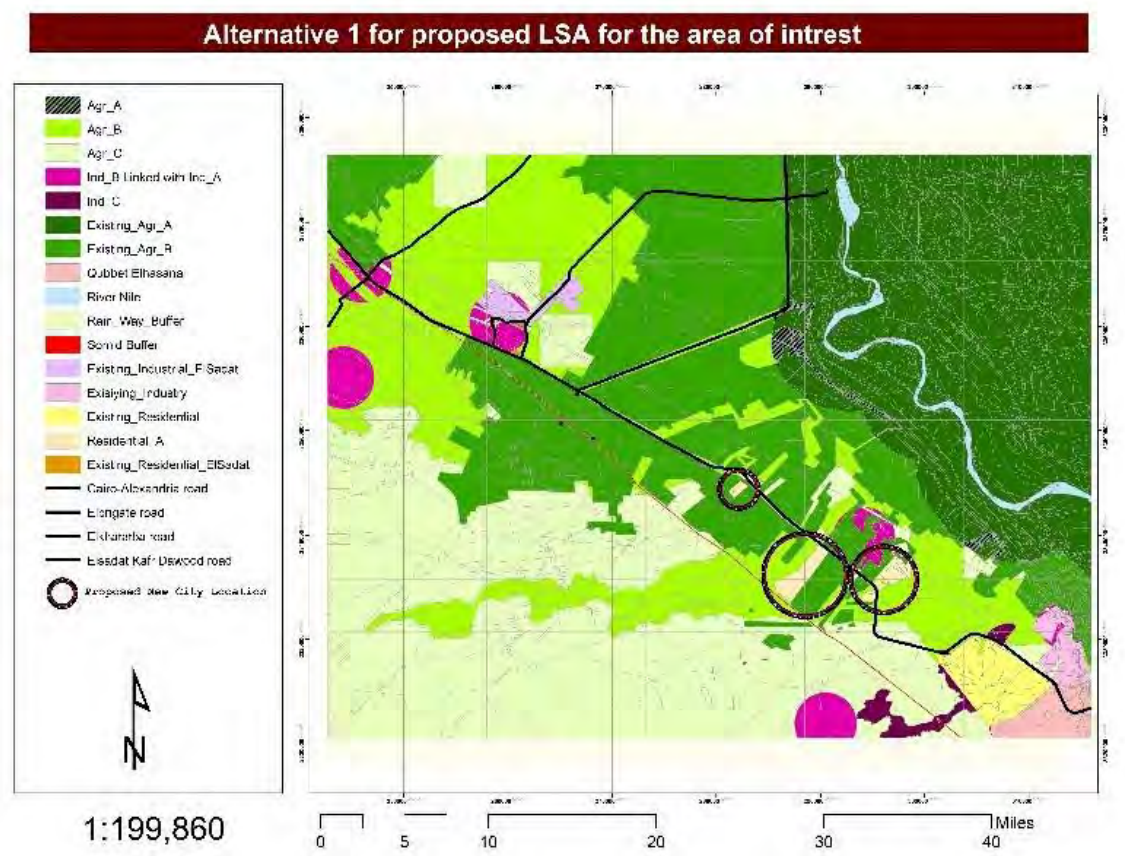

Fig (5) Shows Alternative 1

Source: Researcher

Table 2.shows area of the proposed development sectors

Source: The researcher

\begin{tabular}{|c|c|}
\hline \multicolumn{2}{|c|}{ Source: The researcher } \\
\hline Development Sector & Area in KM2 \\
\hline Agr_A & 25 \\
\hline Agr_B & 776 \\
\hline Total Proposed Agriculture & 1172 \\
\hline Ind_B Linked with Ind_A & 1973 \\
\hline Ind_C & 89 \\
\hline Total Proposed Industry & 23 \\
\hline Proposed Residential & 112 \\
\hline
\end{tabular}




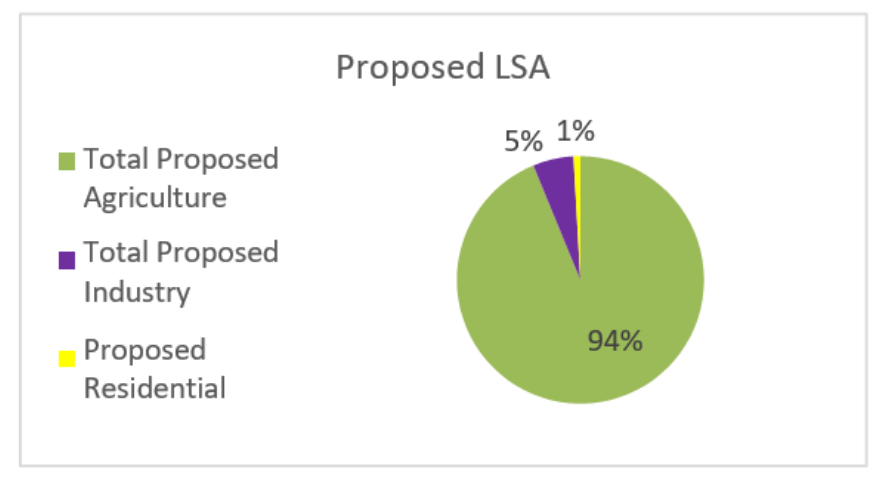

Fig (6) shows the percentage of the proposed LSA

\section{Source: Researcher}

The second LSA planning strategy that was put by the researcher was firstly based on querying the agriculture with type A as a first priority, believing that lands suitable for this type of agriculture should not be replaced by any other development sectors, then searching for the potentials that will support trade with its three categories, afterwards looking for the type of industry that depend on agriculture crops, then looking for both the extractive and transformative industry, followed by querying the data base for the lands suitable for agriculture B the agriculture, and finally exploring the best places that suites the residential development sector. Several results have been concluded from this trial, starting by the LSA suitable for each development sector and the area suitable for each sector which is shown in the following (table 3) and (Fig 7). Based on this type of analysis one location has been proposed for developing new cities with total area $11 \mathrm{KM} 2$. Concerning the economic base for the proposed locations of the new cities, it will be related directly to the proposed LSA of its surrounding area.

Table 3 shows area of the proposed development sectors

Source: Researcher

\begin{tabular}{|c|c|}
\hline \multicolumn{2}{|c|}{ Source: Researcher } \\
\hline Development Sector & Area in KM2 \\
\hline Agr_A & 25 \\
\hline Agr_B & 145 \\
\hline Agr_C & 729 \\
\hline Total Proposed Agriculture & 898 \\
\hline Ind_B Linked with Ind_A & 89 \\
\hline Ind_C & 0.08 \\
\hline Total Proposed Industry & 89 \\
\hline Proposed Residential & 11 \\
\hline Trad_A & 506 \\
\hline Trad_B & 211 \\
\hline Trad_C & 380 \\
\hline Total Proposed Trade & 1108 \\
\hline
\end{tabular}




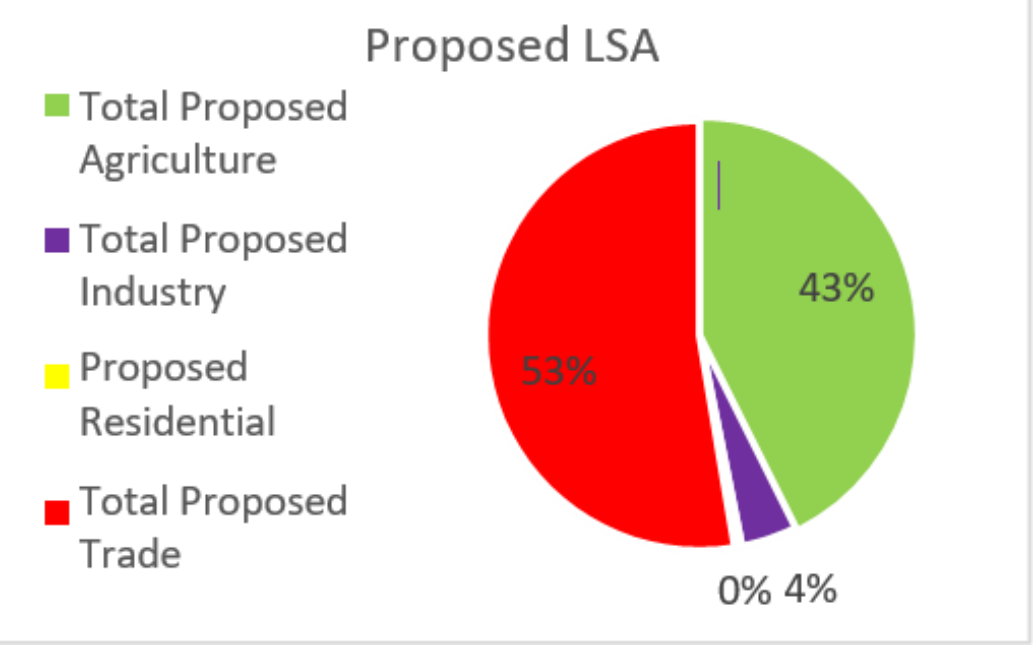

Fig (7) shows the percentage of the proposed LSA

Source: Researcher

\section{Conclusion:}

Due to the current overpopulation that Egypt faces nowadays, the dependency on the traditional ways of planning will not last long; there is no other way except using new technologies in supporting the decision makers.

Using the previously mentioned methodology and applying it on the area of interest gives results for proposing four different locations for the new cities, each of these locations has a different economic base according to the activity distribution. In spite of changing the activities priorities in both the alternatives, it has been found that the agriculture activity almost dominates the area of interest land use. The trade and industry activity have been showed in alternative 2 by a higher percentage than in alternative 1. Changing the alternatives priorities may give us a great number of alternatives all-suite the area of interest potential and constraints, but choosing the best of them depend on planner strategy.

In this study, the researcher examined a new pilot methodological approach tool using GIS and MCDM in LSA field to serves as a decision-making support. This pilot methodology is assisting the planners and decisions makers in deciding the best development sector that suits the area of interest and accordingly it can assist them in choosing best new city location that could attract population upon concrete development sectors and reaches its target within the planned years for it. Moreover, this study could be a guide for the governmental planning organization in combining all the professionals' views in one matrix and applying it by the planners on the study area to be able to reach the setting planning goals upon concrete and analyzed study in LSA field and choosing new city locations.

\section{References:}

1. Aydin, N.Y., Kentel, E. \& Sebnem Duzgun, H., 2013. GIS-based site selection methodology for hybrid renewable energy systems: A case study from western Turkey. Energy Conversion and Management, 70, pp.90-106. Available at: http://www.sciencedirect.com/science/article/pii/S0196890413000848 [Accessed September 17, 2015].

2. El Baroudy, A.A., 2016. Mapping and evaluating land suitability using a GIS-based model. CATENA, 140, pp.96-104.

3. Broesamle, H. et al., 2001. Assessment of solar electricity potentials in North Africa based on satellite data and a geographic information system. Solar Energy, 70(1), pp.1-12.

4. Çekmiș, A., 2016. Fuzzy Logic in Architectural Site Planning Design. Procedia

5. Computer Science, 102, pp.176-182.

6. Chaudhary, P. et al., 2016. Application of an Analytic Hierarchy Process (AHP) in the GIS interface for suitable fire site selection: A case study from Kathmandu Metropolitan City, Nepal. Socio-Economic Planning Sciences, 53, pp.60-71.

7. Cristea, C. \& Jocea, A.F., 2016. GIS Application for Wind Energy. Energy Procedia,

8. 85(November 2015), pp.132-140.

9. Duan, H. \& Huang, L., 2014. Imperialist competitive algorithm optimized artificial neural networks for UCAV global path planning. Neurocomputing, 125, pp.166-171.

10. Effat, H., 2014. Spatial modeling of optimum zones for wind farms using remote sensing and geographic information system, application in the Red Sea, Egypt. Journal of Geographic Information System, (6), pp.358-374

11. Huang, C.-J. et al., 2014. Application of cellular automata and type-2 fuzzy logic to dynamic vehicle path planning. Applied Soft Computing, 19, pp.333-342

12. Jafari, S. \& Zaredar, N., 2010. Land Suitability Analysis using Multi-Attribute Decision

13. Making Approach. International Journal of Environmental Science and Development, 
14. $1(5), \mathrm{pp} .441-445$

15. Javadian, M., Shamskooshki, H. \& Momeni, M., 2011. Application of Sustainable Urban

16. Development in Environmental Suitability Analysis of Educational Land Use by Using Ahp and Gis in Tehran. Procedia Engineering, 21, pp.72-80. Available at:

17. http://linkinghub.elsevier.com/retrieve/pii/S1877705811048235 [Accessed August 7,

18. 2016].

19. Khalifa, M.A., 2011. Redefining slums in Egypt: Unplanned versus unsafe areas. Habitat International, 35(1), pp.40-49. Available at: http://dx.doi.org/10.1016/j.habitatint.2010.03.004

20. Liu, R. et al., 2014. Land-use suitability analysis for urban development in Beijing.

21. Journal of Environmental Management, 145, pp.170-179

22. Mahmoud, A.H.A. \& El-Sayed, M.A., 2011. Development of sustainable urban green areas in Egyptian new cities: The case of El-Sadat City. Landscape and Urban Planning,

23. 101(2), pp.157-170. Available at: http://dx.doi.org/10.1016/j.landurbplan.2011.02.008

24. Malczewski, J., 2004. GIS-based land-use suitability analysis: a critical overview.

25. Progress in Planning, 62(1), pp.3-65.

26. Malczewski, J., 2006. GIS-Based Multicriteria Decision Analysis - A Survey of the

27. Literature. International Journal of Geographical Information Science, 20(7), pp.703-

28. 726.

29. Martos, A. et al., 2016. Towards successful environmental performance of sustainable cities: Intervening sectors. A review. Renewable and Sustainable Energy Reviews, 57, pp.479-495.

30. Montgomery, B. et al., 2016. A GIS-based Logic Scoring of Preference method for evaluation of land capability and suitability for agriculture. Computers and Electronics in Agriculture, 124, pp.340-353.

31. Mrkajić, V.\& Anguelovski, I., 2016. Planning for sustainable mobility in transition cities:

32. Cycling losses and hopes of a revival in Novi Sad, Serbia. Cities, 52, pp.66-78.

33. Nasibov, E., Diker, A.C. \& Nasibov, E., 2016. A multi-criteria route planning model based on fuzzy preference degrees of stops. Applied Soft Computing, 49, pp.13-26.

34. Nguyen, T.T. et al., 2015. Design of a GIS and multi-criteria based land evaluation procedure for sustainable land-use planning at the regional level. Agriculture, Ecosystems

35. \& Environment, (200), pp.1-11.

36. Ning, X. et al., 2016. A multi-attribute model for construction site layout using intuitionistic fuzzy logic. Automation in Construction, 72 , pp.380-387.

37. NUCA, New urban communities authority. http://www.newcities.gov.eg/english/New_Communities/default.aspx. Available at: http://www.newcities.gov.eg/english/default.aspx [Accessed June 20, 2009].

38. RK Brail, R.K., 2001. Planning support systems: integrating geographic information systems, models, and visualization tools R. K. B. Richard E Klosterman, ed., Esri Press.

39. Romano, G. et al., 2015. Multi-criteria decision analysis for land suitability mapping in a rural area of Southern Italy. Land Use Policy, 48, pp.131-143.

40. Temiz, N. \& Tecim, V., 2009. The use of GIS and multi-criteria decision-making as a decision tool in forestry. OR Insight, 22(2), pp.105123 .

41. Wanderer, T. \& Herle, S., 2015. Creating a spatial multi-criteria decision support system for energy-related integrated environmental impact assessment. Environmental Impact Assessment Review, 52, pp.2-8.

42. Waters, N.M., 2002. Modeling the Environment with GIS: A Historical Perspective from Geography B. O. P. and M. P. C. C. Clarke, ed., Upper Saddle River, New Jersey.: Prentice-Hall.

43. Woodfin, T.M., 1993. Design with nature: Ian L. McHarg, Wiley, New York, 1992, 197 pp., ISBN 0-471-55797-8. Landscape and Urban Planning, 23(2), pp.145-147.

44. Xiao, N., Bennett, D.A. \& Armstrong, M.P., 2002. Using evolutionary algorithms to generate alternatives for multiobjective site-search problems. Environment and Planning A, 34(4), pp.639-656.

45. Xu, L. \& Yang, J., 2001. Introduction to multi-criteria decision making and the evidential reasoning approach. Isbn, (106), pp.1-21.

46. Xu, Z. \& Li, Q., 2014. Integrating the empirical models of benchmark land price and GIS technology for sustainability analysis of urban residential development. Habitat International, 44, pp.79-92.

47. Yeo, I.A. \& Yee, J.J., 2014. A proposal for a site location planning model of environmentally friendly urban energy supply plants using an environment and energy geographical information system (E-GIS) database (DB) and an artificial neural network (ANN). Applied Energy, 119 , pp.99-117.

48. Zabihi, H. et al., 2015. Land suitability procedure for sustainable citrus planning using the application of the analytical network process approach and GIS. Computers and Electronics in Agriculture, 117, pp.114-126. 